\title{
ANALISIS PROSES DAN NILAI HATA-HATA MAMBERE PODAH DALAM PERKAWINAN ADAT SIMALUNGUN
}

\author{
Ermina Waruwu ${ }^{1}$, Diana Pramita Sumbayak ${ }^{2}$, Siti Fatimah Br. Sipayung 3 , Pahala Manik ${ }^{4}$ \\ Universitas Prima Indonesia Medan 1,2,3,4 \\ Posel: erminawaruwu@unprimdn.ac.id; dianapramita97@gmail.com
}

\begin{abstract}
The Simalungun tribe has a tradition of carrying out wedding ceremonies. One of the traditions carried out is the hata-hata mambere podah. The problem of this research is how the marriage process of the Simalungun custom, how the hata-hata mambere podah, and how the value contained in the hata-hata mambere podah at the Simalungun traditional wedding ceremony. This study aims to analyze and describe the traditional marriage process of Simalungun, hata-hata mambere podah and the values contained in the hata-hata mambere podah in the process of the marriage of the traditional Simalungun. This study used a descriptive qualitative approach and data was collected using interview methods with recording techniques. The research instrument is the interview guide that is used to interview informants consisting of traditional leaders, residents, brides and residents who have received hata-mambere podah. Data that has been collected was analyzed using qualitative analysis with the content Analysis method.
\end{abstract}

Keywords : Process; V alues; Hata-hata mambere podah; The marriage of Simalungun custom.

\begin{abstract}
Abstrak
Suku Simalungun memiliki tradisi pelaksanaan upacara perkawinan. Salah satu tradisi yang dilakukan ialah hata-hata mambere podah. Permasalahan penelitian ini ialah bagaimana proses perkawinan adat Simalungun, bagaimana hata-bata mambere podah, dan bagaimana nilai yang terkandung dalam hatahata mambere podah pada upacara perkawinan adat Simalungun. Penelitian ini bertujuan untuk menganalisis dan mendeskripsikan proses perkawinan adat Simalungun, hata-hata mambere podah dan nilai-nilai yang terkandung dalam hata-bata mambere podah dalam proses perkawinan adat Simalungun. Penelitian ini menggunakan pendekatan kualitatif deksriptif dan data dikumpulkan menggunakan metode wawancara dengan teknik rekam. Instrumen penelitian ialah pedoman wawancara yang digunakan untuk mewawancarai informan yang terdiri atas tokoh adat, warga, pengantin dan warga yang sudah menerima hata-hata mambere podah. Data yang sudah dikumpulkan dianalisis dengan menggunakan analisis kualitatif dengan metode content Analysis.
\end{abstract}

Kata Kunci:Proses; Nilai; Hata-hata Mambere Podab; Perkawinan Adat Simalungun.

\section{PENDAHULUAN}

Masyarakat Simalungun memiliki sistem nilai wawasan, mentalitas dan sikap yang dapat disebut sebagai salah satu puncak dari budaya daerah yaitu Tolu Sabundulan (Tondong Pangalopan Podah, Sanina Pangalopan Riah, Boru Pangalopan Gogob). Nilai Tolu Sabundulan (Saodoran. Tim Lima, 2013:56-57) secara langsung memberi petunjuk dalam berperilaku. Simalungun merupakan suku atau etnis dengan identitas dan budayanya yang terbentuk dalam proses sejarah perkembangannya. Sebagai identitas, Simalungun dapat dibedakan dari suku-suku bangsa lainnya dari adat, budaya, kebiasaan, sejarah dan segala aspek kehidupannya. Salah satu kekayaan daerah Simalungun ialah uppasa. Adapun pantun Simalungun (uppasa) adalah betuk puisi lama yang mirip dengan pantun dalam sastra melayu, yakni berupa puisi rakyat yang mencakup seluruh lapisan masyarakat dan segala tingkatan umur. Ada uppasa anak-anak, muda-mudi, dan orang tua.

Perkawinan adat Simalungun menampilkan podahatau umpasa dalam bentuk pantun. Misalnya, ketika seorang penatua atau orang tua memberikan nasehat (podah) kepada sepasang pengantin dalam perkawinan, pertama kali harus diberikan suatu umpasa atau pantun, disusul nasehat (podab) yang diberikan kepada sepasang pengantin. Kebiasaaan ini 
disebut Hata-hata mambere podah. Hata-hata mambere podah adalah salah satu kebudayaan adat Simalungun yang biasanya dilangsungkan dalam perkawinan adat. Podah adalah suatu nasihat yang di sampaikan oleh petuah adat dan keluarga kepada kedua mempelai. Ada pun tujuan podah yang diberikan kepada kedua mempelai yakni agar kedua mempelai mampu menerapkan setiap podah dan menjadikan podah sebagai pedoman dalam membina rumah tangga. Hata-hata mambere podah disampaikan bersamaan dengan hidangan dayok binatur (ayam susun) yang merupakan makanan khas Simalungun yang di hidangkan pada acara adat perkawinan. Dayok binatur adalah jenis makanan yang diolah dari daging ayam jantan dan rempah-rempah dan sering dihidangkan dengan dua jenis hidangan yaitu dengan cara dipanggang dan digulai. Dayok binatur yang artinya di atur dengan tujuan agar kehidupan kita teratur seperti keteraturan dari ayam yang sudah diatur sedemikian rupa saat di hidangkan. (Simalungun Center, 2016: 122-152)

Perkawinan adat Simalungun memiliki proses atau tahapan yaitu Pertama; Pra nikah yang terdiri dari Mangarisika, Marbori-hori Dinding, Marbusip, Pudun Sauta, Martumpol, Martonggo Raja. Kedua; Pesta Perkawinan yang terdiri dari 1) proses perkawinan di Gereja, 2) Proses perkawinan di Gedung. Adapun tata urutan perkawinan di Gedung dimulai dengan melaksanakan Prosesi a) Hata-hata Mambere Podah. Raja parhata/protokol pihak wanita meminta semua dongan tubu/semarganya bersiap untuk menyambut dan menerima kedatangan rombongan hula-hula dan tulang. Raja parhata/protokol pihak perempuan memberi tahu kepada Hula-hula, bahwa Suhut pihak laki-laki sudah siap menyambut dan menerima kedatangan Hula-hula. Setelah Hula-hula mengatakan mereka sudah siap untuk masuk, Raja parhata/protokol pihak wanita/Pria mempersilakan masuk dengan menyebut satu persatu secara berurutan yakni Hula-bula, Tulang, Bona Tulang, Bonaniari, Hula-bula namarhamaranggi, Hula-bula anak manjae, dengan permintaan agar mereka bersama-sama masuk dan menyerahkan pengaturan selanjutya kepada hula-hula. Semua appang naopat, tolu sabundulan ini akan menyampaikan hata-hata mambere podah kepada kedua mempelai pada saat proses perkawinan adat yang dilaksanakan di gedung. b) Menyerahkan tanda makanan (Tudu-tudu ni sipanganon), c) Menyerahkan dengke (ikan oleh suhut pihak wanita ), d) Makan bersama, e) Membagi Jambar (tanda makanan adat). Ketiga; Pasca Pernikahan, prosesi ini terdiri atas, a) Pesta Unjuk, b) Mangihut di ampang (dialap jual), c) Ditaruhon jual, d) Paranak makan bersama di tempat kediaman pria (Daulat ni si panganon), e) Paulak Unea, f) Manjahea, g) Maningkir Tangga

Hata-hata mambere podah sebagai salah satu tradisi lisan yang terdapat dalam budaya adat Simalungun. Tradisi lisan (Sibarani, 2014: 43-47; 125-126) adalah kegiatan budaya tradisional suatu masyarakat yang diwariskan secara turun-temurun dengan media lisan dari suatu generasi ke generasi lain baik tradisi itu berupa susunan kata-kata lisan (verbal) maupun tradisi lain yang bukan lisan (non-verbal). Tradisi lisan dapat berupa berbagai pengetahuan dan adat istiadat yang secara turun temurun disampaikan secara lisan yang mencakup tidak hanya berupa cerita rakyat, legenda atau mitos. Tradisi lisan mencakup atau berkaitan dengan sejarah, hukum adat, upacara adat, upacara keagamaan, ramuan tradisional, dan pengobatan. Semua itu dapat dikatakan sebagai tradisi lisan dan proses penyebarannya pun biasanya dilakukan secara lisan atau dilisankan (Karkono, 2013: 272273). Tradisi lisan dapat disebut juga sebagai tradisi budaya. Hal penting yang menjadi isi 
dan yang perlu diperhatikan dalam kandungan kebudayaan, tradisi budaya atau tradisi lisan ialah makna dan fungsi, nilai dan norma budaya serta kearifan lokal. Setiap etnik di Indonesia termasuk etinik Simalungun memiliki banyak nilai budaya yang dapat dimanfaatkan untuk menata kehidupan masyarakat dalam rangka membentuk kepribadian yang kuat untuk tujuan pembentukan kedamaian dan peningkatan kesejahteraan masyarakat. Nilai-nilai budaya dari berbagai etnik di Indonesia pada umumnya saling mengisi dan saling melengkapi untuk satu kearifan lokal.

Tradisi yang bersifat lisan merupakan norma-norma adat yang hendaknya dipatuhi oleh anggota masyarakatnya (Astika: 2014). Setiap ada upacara adat, aturan dalam upacara itu dilakukan sesuai dengan apa yang telah dilakukan oleh nenek moyang sebelumnya. Danandjaja dalam Hari (2015:7) mengangkat pendapat pakar tradisi lisan William R. Bascom, bahwa secara umum tradisi lisan mempunyai fungsi penting. Fungsi tersebut sangat berhubungan dengan masyarakat antara lain 1) Tradisi lisan berfungsi sebagai cerminan angan-angan suatu kolektif. Misalnya, dalam masyarakat Jawa, ada kepercayaan pada suatu masa "akan datang ratu adil". Kepercayaan itu sebagai cerminan harapan, citacita tentang citra pemimpin yang ideal, adil, makmur, dan berwibawa. Pada sisi lain kemungkinan besar kepercayaan itu juga menggambarkan 'pemimpin yang sekarang itu" sangat mengecewakan hati rakyatnya, kacau, tidak adil, dan tidak berwibawa, 2) Tradisi lisan berfungsi sebagai alat pendidikan. Tradisi lisan yang berfungsi sebagai tradisi lisan akan memberikan pengetahuan, pengertian, dan pemahaman terhadap nilai-nilai yang hidup dan berkembang di masyarakat yang ditanamkan sejak masa kanak-kanak, 3) Tradisi lisan berfungsi sebagai alat pemaksa atau pengontrol norma-norma. Masyarakat selalu dipatuhi anggota kolektifnya. Hal ini dapat kita jumpai apabila isi dalam sastra lisan tersebut mengungkapkan peraturan-peraturan atau hukum-hukum yang berkembang di masyarakat baik secara eksplisit maupun implisit. Hukum tersebut diungkapkan agar setiap individu tetap menjaga harmonisasi dalam konteks hubungannya dengan Tuhan, alam sekitar dan masyarakat.

Pada kenyataannya zaman berkembang diikuti kemajuan teknologi, sehingga mulailah para anak muda dan anggota masyarakat suatu etnik secara sadar maupun tidak sadar mulai melupakan kebiasaan dalam adat. Kalaupun dikatakan tidak melupakan, paling tidak telah terjadi pengurangan atau penyederhanaan aturan dalam pelaksanaan upacara adat dalam masyarakat tersebut. Oleh karena itu, peneliti memaparkan berbagai fenomena atau kenyataan terkait dengan permasalahan penelitian yaitu: pertama; di jaman sekarang ini, hata-hata mambere podah telah dilupakan oleh banyak masyarakat Simalungun, khususnya masyarakat yang tinggal di daerah perkotaan. Kedua; kebudayaan hata-hata mambere podah hampir tidak terlaksana lagi dalam perkawinan adat simalungun karena masyarakat perkotaan lebih mengutamakan proses adat perkawinan yang lebih praktis Ketiga; Kurangnya pemahaman dan pengetahuan masyarakat modern tentang nilai dan fungsi hata bata mambere podah dalam adat perkawinan Simalungun, Keempat; Kurangnya rasa ingin tahu generasi muda sekarang tentang hata-hata mambere podah dalam perkawinan adat simalungun. Kelima; masyarakat modern telah banyak melupakan ajaran hata-hata mambere podah dalam perkawinan adat simalungun sehingga tidak dijadikan sebagai pemertahanan hidup perkawinan. Peneliti juga telah menemukan masalah berdasarkan hasil prapenelitian tanggal 
29 Maret 2019 dengan mewawancarai kepada 3 (tiga) orang masyarakat Simalungun di Desa Nagori Tani yakni terdapat permasalahan perkawinan seperti perbedaan agama, dan salab satu yang sering terjadi yaitu tentang tata pelaksanaan dalam sebuab perkawinan Adat Simalugun.

Berdasarkan identifikasi masalah yan diuraikan di atas maka peneliti menentukan permasalahan dalam penelitian ini yaitu 1) Bagaimana proses perkawinan adat Simalungun?, 2) Bagaimana hata-hata mambere podah dalam proses perkawinan adat Simalungun?, 3) Apa saja nilai-nilai hata-hata mambere podah dalam perkawinan adat Simalungun. Penelitian ini bertujuan untuk menggali, menganalisis dan mendeskripsikan 1) Proses perkawinan adat Simalungun, 2) Hata-hata mambere podah dalam proses perkawinan adat Simalungun, 3) Nilai-nilai yang terdapat dalam Hata-hata Mambere Podah pada perkawinan adat Simalungun. Penelitian ini penting 1) agar masyarakat modern dapat mempertahankan tradisi budaya dan kearifan lokal mengenai proses perkawinan Simalungun, 2) Nilai-nilai yang terdapat dalam Hata-hata Mambere Podah pada perkawinan adat Simalungun sebagai salah satu tawaran solusi untuk mempertahankan tradisi lisan yang dapat digunakan oleh masyarakat sebagai pranata kehidupan sosial, 3) Penelitian ini penting diperkenalkan kepada generasi muda khususnya para pelajar yang masih duduk dibangku pendidikan bahwa salah satu sumber pranata sosial yang mengatur kehidupan masyarakat ialah Hata-hata mambere podah yang terdapat dalam proses perkawinan adat Simalungun. Berdasarkan urgensi penelitian ini, peneliti melakukan penelitian yang berjudul Analisis Proses dan Nilai Hata-Hata Mambere Podah Dalam Perkawinan Adat Simalungun.

\section{METODE PENELITIAN}

Pendekatan atau metode penelitian yang digunakan dalam penelitian ini ialah kualitatif (Sugiyono, 2015). Penelitian dilakukan di Desa Nagori Tani,Kecamatan Silau Kahean, Kabupaten Simalungun. Penelitian dilakukan selama 3 (tiga) bulan mulai Maret sampai dengan Mei 2019. Ada pun subyek dalam penelitian ini adalah informan kunci yang dipilih atau ditentukan dengan cara purposive sampling yang terdiri atas Rajiman Saragih (Penatua), Damman Sipayung (Tokoh adat), Kiman Purba/ Ny, B. Damanik (penerima hata-hata mambere podah), J. Sumbayak/Ny. M. Hutabarat (penerima hata-hata mambere podah), hula-hula, Tulang, Bona Tulang, Tulang Robot, Bonaniari, Hula-hula namarhamaranggi, Hula-hula anak manjae. Teknik pengumpulan data yang digunakan dalam penelitian yakni melakukan wawancara kepada informan yang sudah ditetapkan dan teknik observasi Instrumen penelitian yang dikhususkan untuk mengambil data lapangan yakni berupa pedoman wawancara, pedoman observasi dan dokumentasi foto.

\section{HASIL DAN PEMBAHASAN}

Berdasarkan data penelitian yang diperoleh di Simalungun, Desa Nagori Tani Kecamatan Silau Kahean, peneliti memaparkan hasil-hasil penelitian sebagai berikut.

\section{Proses Perkawinan Adat Simalungun}

Simalungun mempunyai adat perkawinan yan khas. Ada perkawinan Simalungun memiliki proses atau urutan yang terdiri atas:

1) Pajabu Parsahapan/Mangarisiska artinya meminang. Proses ini adalah kunjungan utusan dari pihak mempelai pria yang yan bersifat tidak resmi ke tempat mempelai wanita 
denan tujuan penjajakan. Jika pintu terbuka untuk mengadakan peminangan maka pihak orang tua memberikan "tanda mau" (tanda holong) dan pihak pria memberikan "tanda mata". Ada jenis-barang-barang yang diperlukan dalam proses ini yakni kain, cincin emas dan lain-lain.

2) Marhori-hori dinding / Marbusip (berbicara), artinya ada pembicaraan antara kedua belah pihak yang melamar dan yang dilamar. Pembicaraan ini bersifat terbatas yakni bersama dengan kerabat yang berhubungan dekat. Pembicaraan ini masih belum bersifat umum.

3) Marhata sinamot, yaitu proses dimana pihak kerabat pria (dalam jumlah yang terbatas) datang kepada kerabat wanita untuk melakukan marbata sinamot atau membahas tentang uang jujur (tubor) yang akan dipersiapkan.

4) Pudun Saud (mengundang krabat) adalah pesta kerabat pria tanpa hula-hula mengantarkan wadah sumpit berisi nasi dan lauk pauk (yang sudah di sembelih) yang diterima oleh parboru dan setelah makan bersama denga berbagi jambar jubut (daging) untuk anggota kerabat yaitu Hula-hula, Dongan tubu, Boru, Pengetuai, Pariban. Diakhir pudun saud maka dari keluarga wanita dan pria bersepakat kiriman Martupol dan Pamasu-masuon.

5) Martuppol adalah penandatanganan persetujuan pernikahan oleh orang tua kedua belah pihak atas rencana perkawinan anak-anak mereka yang dihadiri pejabat gereja. Tata cara martuppol dilaksanakan oleh pejabat gereja sesuai dengan ketentuan yang berlaku. Tindak lanjut martuppol adalah pejabat gereja mewartakan rencana pernikahan dari kedua mempelai melalui warta gereja.

6) Martonggo Raja / Mariah Raja adalah adalah suatu acara pra pesta/acara yang diadakan secara seremonial oleh penyelenggara pesta. Acara ini dimaksudkan dengan tujuan pembagian kerja pada masyarakat sekitar dan permohonan izin pengunaan fasilitas umum terkait pesta perkawinan.

7) Pamasu-masuan (pemberkatan pernikahan) ialah proses pengesahan pernikahan kedua mempelai menurut tata cara gereja. Setelah pemberkatan pernikahan selesai maka kedua mempelai sudah sah sebagai suami-istri.

8) Pesta unjuk adalah suatu acara perayaan yang bersifat sukacita atas pernikahan putra dan putri.

9) Mangibut di Ampang (dialop jual) adalah mempelai wanita dibawa ke tempat mempelai pria yang dielu-elukan kerabat pria dengan dengan diiringi jual berisi makanan bertutup ulos yang disediakan oleh pihak kerabat pria.

10) Ditarohon jual artinya jika pesta untuk pernikahan itu dilakukan di rumah mempelai pria, maka mempelai wanita dibolehkan pulang ke tempat orang tuannya untuk kemudian diantar lagi oleh para Namborunya ke tempat Namborunya. Dalam hal ini paranak wajib memberikan upa manaru (upah mengantar) sedang dalam dialap jual upa, manaru tidak dikenal.

11) Paranak ialah makan bersama di tempat kediaman si pria (daulat ni sipanganon),

12) Paulak unea, artinya setelah satu, tiga lima atau tujuh hari si wanita tinggal bersama dengan suaminya, maka paranak, ( pihak dari keluarga laki- laki) pengantin pria bersama istrinya pergi ke rumah mertuanya untuk menyatakan terima kasih atas berjalannya acara pernikahan dengan baik. Setelah selesai acarapaulak unea (setelah pesta, pibak laki- 
laki datang bertamu kerumah pihak wanita) paranak kembali ke kampung halaman atau rumahnya dan selanjutnya memulai hidup baru.

13) Manjahea, artinya setelah beberapa pengantin pria dan wanita dalam waktu lama sudah menjalani hidup berumah tangga (kalau pria tersebut bukan anak bungsu), maka ia akan dipajae, yaitu dipisah rumah (tempat tinggal) dan mata pencaharian.

14) Maningkir tangga artinya setelah beberapa lama pengantin pria dan wanita berumah tangga dan mandiri dan juga urusan rumah tangga dan mata pencahariannya telah dipisah dari orang tua si laki- laki, maka parboru datang berkunjung kepada paranak dengan maksud maningkir tangga. Maningkir tangga dimaksudkan kunjungan sebagai rumah tangga pengantin baru. Dalam kunjungan ini parboru membawakan makanan yang terdiri atas nasi dan lauk pauk, dengke sitio- tio dan dengke simundur-mundur.

\section{Perlengkapan Perkawinan Adat Simalungun}

Perkawinan adat Simalungun mempunyai benda-benda atau perlengkapan yang digunakan dalam pesta perkawinan. Perlengkapan tersebut antara lain Gotong (kopiah lakilaki ), Bulang (tudung Wanita), Suri-suri (Selendang Wanita), Bajut (Tas Wanita), Keris (Suhul gading ). Selain itu ada benda-bendayang diperlukan dalam proses adat yakni 1) demban sebagai penanda atas kedatangan dan penghormatan kepadatondong (yang memegang peran dan pemilik pesta ( orang tua) . 2) Ulos bermakna sebagai bagian adat Simalungun yang akan diberikan kepada boru (penyandang pesta). 3) Tapongan yang bermakna sebagai simbol adat yang sah. Tapongan disebut juga maralop sewaktu menyampaikan mahar. 4) Beras yang bermakna menyatakan selamat. 5) Patappei parsahapan dengan menggunakan benda mardemban gunringan yang berfungsi untuk menyampaikan mahar. 6) Dayok binatur yang bermakna agar kelak keluarga yang telah menerima hata-hata mambere podah memiliki keteraturan dalam membina rumah tangga mereka. Dayok binatur tersusun sangat rapi maka dari itu disebut dengan dayok binatur artinya ayam yang tersusun rapi.

Secara lengkap perlengkapan atau benda dan makna-makna dari setiap benda yang digunakan dalam perkawinan adat Simalungun dapat dijelaskan satu persatu.

1) Gotong

Gotong adalah penutup kepala pria Simalungun, berbentuk seperti kerucut, biasanya gotong dipergunakan dalam acara pesta dan acara resmi lainnya yang bernuansa budaya simalungun. Gotong pada dasarnya dipakai oleh pria simalungun yang sudah berumah tangga pada suatu acara pesta, dimana yang empunya pesta adalah mereka atau dalam bahasa Simalungun dinamakan Suhut. Pada gotong ada simbol pagar atau rantai gotong yang masing-masing terbuat dari perak maupun emas. Ada juga Doramani yang merupakan perwujudan simbol hirarki pada masa pemerintahan feodalisme di Simalungun. Doramani merupakan hiasan gotong di Simalungun letaknya di sebelah kiri gotong, bergantung dengan jumlah yang ganjil dan ukuran yang sama besar.

2) Bajud Pundul

Bajud Pundul adalah perlengkapan wanita, tempat perangkat sirih bagi tamu. Melambangkan persaudaraan terhadap sesama. Boli/appuran partadingan: mahar batu apuran: uang adat yang diletakkan di atas sirih di dalam piring. Boras tengger: beras keras. Bah: Air bagod: Nira babah: mulut. Dearan: Lebih Baik Dayok Binatur: Air yang sudah 
dimasak diletakkan didalam piring kaca. Dohor: Dekat Daoh: Jauh Dakdanak: Anak-anak. Dalahi: Laki-laki Demban Dolok: Sirih. Dayok Binatur: Makanan adat yang terdiri dari ayam yang setelah dimasak sedemikian rupa,diatur sedemikian sebagaiman ayam ketika masih hidup. Dongan Demban Nabayu: Kawan Sirih Pengantin Baru Demban Sayur/Demban Tangan-tangan.

3) Etek

Etek, sebagai sebagai ganti Gotong atau etek, sejenis tutup kepala bagi kaum pria yang mengandung makna kepemimpinan di tengah keluarga maupun masyarakat. Grama Golang banggal emas: Hiasan gotong pria. Hudung-hudung emas: Sejenis kain penutup tubuh hasil tenunan Simalungun mengandung makna aman dari gangguan serta sehat jasmani dan rohani rejeki selalu bertambah.

4) Hiou

Hiou biasanya dililitkan melingkar tubuh dan rambu-rambunya dibuat ke bagian depan, menghadap sisi kiri pemakai mulai dari atas pinggang sampai mata kaki. Pangkal Hiou pada batas pinggang. Hiou ini sama seperti Ragi Sapot tetapi pada ujung luarnya dilengkapi dengan jumbai dan kain ini bisa dikenakan oleh siapapun.

5) Suri-suri, disandang di bahu sebelah kanan dan memiliki panjang yang sama di bagian depan dan belakang.

6) Toluk Balanga ialah pakaian atas pria berupa jas tanpa kerah yang melingkar di leher berwarna hitam pekat (seperti kuali).

7) Pita atau Benang Emas, berwarna emas yang dirajut atau tergantung antara kantung sebelah kiri hingga bros (kancing) jas tanpa kerah (toluk balanga).

8) Bulang, digunakan dalam bentuk bulang sulappei. Untuk membedakan bulang yang digunakan pengantin perempuan dengan yang digunakan basubuuton (tuan rumah, mertua/ibunya) maka bulang pengantin adalah bulang sulappei dengan warna asli Simalungun (merah hati/kecoklatan).

9) Bujud Hundul, dikempit pada siku lengan kiri merapat pada pinggang sebelah kiri,

10) Soja, yaitu pakaian atas pengantin wanita berupa kebaya lengan panjang dan berwarna putih cerah

11) Sutting, yaitu hiasan bulang berupa cincin berwarna emas yang disematkan pada kedua sisi bulang di bagian telinga

12) Sinokkod Baggal, yaitu kalung besar berwarna emas yang digantung di leher dan tampak berada di luar soja.

13) Podding yaitu ikat pinggang yang dipakai melingkar dipinggang.

\section{Hata-Hata Mambere Podah dalam Perkawinan Adat Simalungun}

Hata-hata mambere podah dalam perkawinan adat Simalungun merupakan proses penting. Hata-hata mambere podah disampaikan oleh Tondong terdiri dari enam orang, yaitu : Tondong ni tondong, tondong jabu, tondong bonaniari, tondong mataniari, tondong boru, tondong sanina. Namun, yang pertama dan utama menyampaikan podah dalam proses Perkawinan Adat Simalungun adalah orang tua, Tulang, Sanina, dan yang terakhir adalah Boru. Berdasarkan data wawancara dan observasi, secara faktual ditemukan bahwa yang menyampaikan Podah (nasehat) dalam proses Perkawinan Adat Simalungun yaitu ampang 
naopat Tolu saodoran terdiri atas : Tondong, Tulang, Bona tulang, Tulang Robot, tondong bonaniari, parsaninaon/parbapaon, anak boru manjae. Kemudian, oleh orang tua, dan organisasi dari parsahutan dan Gereja. Hata-hata mambere podah dalam perkawinan adat Simalungun secara umum berisikan tentang tentang kerukunan, kedamaian, dan kasih Tuhan dalam rumah tangga pengantin, isi podah Simalungun seperti digambarkan berikut ini:

"Dear- dear manasiam namarumah tangga, ulang maringori, sai pandei ma manempatkon diri, bani namarsimatua pakon namarorang tua, sonai homani bani namarsanina, ringgas huparmingguan, anggo domma Ibu, ikutma bani acarani Parinangon, anggo bapa ikut ma bani parbapaon. Ase lambin dear namarlingkungan anjaha dear marparlahou bani halak namabuei"

Berdasarkan data di atas, maka podah berisikan: "baik- baiklah dalam berumah tangga, saling menghormati satu sama lain, baik kepada orang tua dari pihak laki- laki maupun pihak perempuan, maupun terhadap saudara yang lain, rajin mengikuti acara dalam keluarga, rajin mengikuti acara dalam perkumpulan lingkungan, dan Gereja.

\section{Nilai-Nilai Hata-Hata Mambere Podah Dalam Perkawinan Adat Simalungun}

Hata-Hata Mambere Podah dalam Perkawinan Adat Simalungun termasuk proses penting dan memiliki nilai. Nilai-nilai yang terkandung dalam Podah, dijelaskan antara lain 1) Nilai Agama (Religius)

Podah memiliki nilai agama atau religius yakni rajin berdoa dan pergi ke Gereja. Podah ini berisikan agar kedua mempelai dapat membina keluarga sesuai dengan ajaran agama sehingga keluarga yang baru dibangun menjadi keluarga yang taat beribadah dan takut akan Tuhan. Berdasarkan temuan penelitian podah berisikan " Ringgas huparmingguan, ulang lupa martonggo, Sai roh dohorni ma bubani Tuban". Artinya Rajinlah beribadah, serta jangan lupa berdoa, dan dekatlah selalu kepada Tuhan.Nilai religius bertujuan (Rina Yesika Kusuma Wardani, 2017) Untuk memohon keselamatan dan kelancaran sertah berkah dalam menjalankan rumah tangga kepada Tuhan Yang Maha Esa.

2) Nilai Moral

Podah dalam perkawinan adat Simalungun mengandung nilai sosial yakni kedua mempelai yang akan membina rumah tangga dapat menjadi keluarga yang saling menghargai satu sama lain mulai dari keluarga maupun di lingkungan masyarakatnya, menjaga martabat agar baik dipandang oleh masyarakat. Selain itu, kedua mempelai memupuk dan melakukan sikap saling menghargai bersika toleransi antar keluarga. Podah perkawinan Simalungun yakni "Sai marsiharganan ma nasian na marfamili, sai hormat ma nasiam mar orang tua", artinya Saling menghormatilah sesama saudara, dan hormatlah terhadap orang tua. Oleh karena itu, hata-hata mambere podah memiliki nilai moral (M.Juwaini, 2018) yang mengandung prinsip sikap baik, prinsip keadilan dan prinsip hormat terhadap diri sendiri.

3) Nilai Sosial

Nilai sosial ada dalam podah yang biasanya disampaikan kepada kedua mempelai dalam proses perkawinan adat Simalungun. Nilai sosial yang terdapat dalam podah tersebut yakni ketika kedua mempelai sudah berumah tangga harus mampu dan pandai berbaur dengan masyarakat. Sebagai contoh, jika dalam lingkungan ada sebuah perkumpulan atau acara-acara seperti dari Gereja, atau acara Perkawinan Adat Simalungun, maka kedua 
mempelai harus ikut membantu, baik dari pihak suami maupun istri. Pesan ini sama seperti yang disampaikan dalam Podah Simalungun yaitu "Sai ringgasma namarsosialisasi, anggo dong parkumpulan kaum ibu, sai odorma mangihut, age sonai bani kaum bapak, sai marsaorma bani kaum bapak, ase lambin dear namarsosial bani parsabutaan", artinya Rajinlah bersosialisasi, jika ada perkumpulan kaum Ibu, bergabunglah di dalamnya, begitu juga sebaliknya, jika ada kaum bapak, bergabunglah juga terhadap kaum bapak, agar semakin baik dalam perkumpulan yang bermasyarakat. Nilai Sosial yang dilaksanakan dalam hidup bermasyarakat (Riauwati, 2017) yakni menghormati orang lain, kegotong royongan, mempererat bubungan kekeluargaan, kerukunan, dan sebagai wujud pelestarian adat istiadat dalam masyarakat.

4) Nilai Budaya

Podah yang disampaikan kepada kedua mempelai sebagai anggota masyarakat yakni ikut melestarikan budaya Simalungun seperti pakaian adat yang yang digunakan dalam perkawinan dan juga urutan-urutan dan aturan yang dilaksanakan di dalam suatu adat perkawinan simalungun. Budaya Simalungun seperti cara berpakaian, proses acara, sampai pada Podah (Nasehat) agar diwariskan sampai kepanpun kepada anak cucu. Isi podah adat Simalungun yakni "Ulang lupa bona, balani bani dasarni budaya ma namam bentuk haganup jolma", artinya Jangan lupa adat, karena pada dasarnya budaya lah yang membentuk kebiasan seseorang. Oleh karena itu pelaksanaan perkawinan Adat simalungun harus dibudidayakan, dilestarikan, tetap diteruskan kepada anak cucu dengan tetap mengikuti silsilah adat simalungun, dan selalu berpegang teguh terhadap falsafah Habonaron Do Bona (Kebenaran adalah pokoknya) menjadi filosofi bidup orang Simalungun, yaitu suatu sikap, etika perilaku dan ideologi yang berlandas atas kebenaran. Nilai -nilai Habonaron Do Bona menjadi pedoman dan penuntun bidup yaitu: setiap perilaku masyarakat Simalungun barus takut akan Tuban Allah, aktualisasinya adalah melaksanakan kewajiban agamanya dengan baik dan benar.

Berdasarkan hasil penelitian maka terdapat temuan penelitian yang bersifat urgen yakni hata-hata mambere podah sangat bermanfaat dalam kehidupan rumah tangga. Berbagai manfaat tersebut antara lain 1) melanggengkan rumah tangga yang dibangun, 2) menjadikan keluarga bahagia dan jauh dari pertengkaran, 3) Rumah tangga dipenuhi oleh cinta kasih, 4) Pegangan hidup dan harus dilaksanakan oleh kedua mempelai agar hidup keluarga dapat menjadi lebih baik, rukun, bahagia, sejahtera dan pastinya jauh dari kata perceraian. Manfaat ini dirasakan oleh masyarakat: "Baen ma Podah on sebagai joloman bani parumabtanggan nasiam, ulang sai martinggili,sai marsiharganan masiam nadua bani mambangun rumah tangga, daob ma paringoran, sai marpangharapan ma bai Tuhanta Naibata, sai horas horasma nasiam sadarion sampai maranak marboru", artinya Buatlah nasehat ini sebagai pegangan dalam membangun rumah tangga kalian, jangan ada perselisihan, dan selalulah saling menghargai diantara kalian berdua dalam membangun rumah tangga, jauhlah segala yang tidak diinginkan, dan berharaplah kepada Tuhan, hari ini bahkan sampai kalian mempunyai cucu. Oleh karena itu setiap perkawinan yang dilaksanakan secara khas sesuai dengan adat dan istiadat memiliki manfaat serta tujuan membentuk rumah tangga dan hubungan kekerabatan yang rukun dan damai, serta bahagia dan kekal. 


\section{SIMPULAN}

Hata-hata Mambere Podah adalah salah satu proses penting dalam perkawinan Adat Simalungun. Hata-hata Mambere Podah sebagai nasehat (podab) yang disampaikan kepada kedua mempelai pada saat upacara perkawinan adat Simalungun. Upacara perkawina adat Simalungun memiliki proses dan urutan pelaksanaan yang teratur yang dimulai dari Pajabu Parsahapan/Mangarisiska artinya meminang, Marbori-hori dinding/ Marbusip (berbicara), Marhata sinamot, Pudun Saud (mengundang kerabat), Martuppol, Martonggo Raja / Mariah Raja, Pamasu-masuan (pemberkatan pernikahan), Pesta unjuk, Mangihut di Ampang (dialop jual), Ditarohon jual, Paranak, Paulak unea, Manjahea, Maningkir tangga.

Hata-hata mambere podah disampaikan oleh Tondong terdiri dari enam orang, yaitu : Tondong ni tondong, tondong jabu, tondong bonaniari, tondong mataniari, tondong boru, tondong sanina. Hata-hata mambere podah dalam perkawinan adat Simalungun secara umum berisikan tentang tentang kerukunan, kedamaian, dan kasih Tuhan dalam rumah tangga pengantin yang akan membentuk rumah tangga baru. Hata-hata mambere podah mengandung nilai-nilai antara lain 1) Nilai Agama (Religius) yakni agar kedua mempelai dapat membina keluarga sesuai dengan ajaran agama, 2) Nilai Sosial yakni agar kedua mempelai memupuk dan melakukan sikap saling mengharga, bersikap toleransi antar keluarga. 3) Nilai Sosial yakni menghormati orang lain, kegotong royongan, mempererat hubungan kekeluargaan, kerukunan, dan sebagai wujud pelestarian adat istiadat dalam masyarakat. 4) Nilai Budaya yakni agar pelaksanaan perkawinan Adat simalungun tetap dibudidayakan, dilestarikan, tetap diteruskan kepada anak cucu dengan berpegang teguh terhadap falsafah Habonaron Do Bona.

\section{DAFTAR PUSTAKA}

Agustina Grace, dkk. 2018. Tunjuk Ajar Dalam Upacara Perkawinan Suku Batak Simalungun.Jurnal Pendidikan. 18(6): 2-11

Aprilia Vivi. 2016.Makna Simbolik Komunikasi Budaya Dalam Upacara Adat Perkawinan Masyarakat Batak Toba di Pekan Baru. Jurnal Pendidikan.16 (10):3-15

Astika, I Made, dkk, 2014. Sastra Lisan dan Teori Penerapannya.Yogyakarta: Graha Ilmu.

Riauwati, Suhardi .2017. Analisis Nilai- Nilai Budaya (Melayu) Dalam sastra Lisan Masyarakat Kota Tanjung Pinang. Jurnal pendidikan. 17 (01):2-9

Sandi Hari. 2015.Marhata-bata Sastra Lisan Pada Tradisi Mulak Ari di Nagari Rabi Jonggor Kecamatan Gunung Tuleh Kabupaten Pasaman Barat Sumatera Barat. Artikel Ilmiah.15(10): $5-10$

Saodoran Tim Lima.2013. Mengenal Kabupaten Simalungun.Medan: Mitra .

Sibarani, Robert. 2014. Kearifan Lokal-Hakikat, Peran, dan Metode Tradisi Lisan. Jakarta: Asosiasi Tradisi Lisan (ATL).

Simalungun Center.2016.Supremasi Hukum dan Pembangunan Rakyat Tertindas Simalungun.Simalungun: Transisi

Sinuhaji Minah.2013.Pelestarian Adat dalam Upacara Perkawinan Masyarakat batak Karo Sebagai Atraksi Wisata dalam Menunjang Kepariwisataan di Kabupaten daerah Tingkat II Karo. Jurnal Pendidikan.13(Vol 5.No.1-2013) : 2-10 
SeBaSa: Jurnal Pendidikan Bahasa dan Sastra Indonesia

Sugiyono. 2015. Metode Penelitian Pendidikan Pendekatan Kuantitatif, Kualitatif, dan R\&oD. Bandung: Alfabeta 